\title{
Berkeley, Human Agency and Divine Concurrentism
}

\section{Citation}

McDonough, Jeffrey K. 2008. Berkeley, Human Agency and Divine Concurrentism. Journal of the History of Philosophy 46(4): 567-590.

\section{Published Version}

doi:10.1353/hph.0.0056

\section{Permanent link}

http://nrs.harvard.edu/urn-3:HUL.InstRepos:5130438

\section{Terms of Use}

This article was downloaded from Harvard University's DASH repository, and is made available under the terms and conditions applicable to Open Access Policy Articles, as set forth at http:// nrs.harvard.edu/urn-3:HUL.InstRepos:dash.current.terms-of-use\#OAP

\section{Share Your Story}

The Harvard community has made this article openly available.

Please share how this access benefits you. Submit a story.

Accessibility 


\title{
Forthcoming Journal of the History of Philosophy... .
}

\begin{abstract}
This paper offers a sympathetic reading of Berkeley's account of human agency. The first section briefly revisits three options concerning the relationship between human and divine agency available to theistically minded philosophers in the medieval and early modern eras. The second argues that of those three views only the position of concurrentism is consistent with Berkeley's texts. The third section explores Berkeley's reasons for adopting concurrentism by highlighting three motivating considerations drawn from his larger philosophical system. Finally, the fourth section attempts to flesh out Berkeley's understanding of human activity by looking at how we might understand his claim that "we move our legs ourselves" in light of his commitments to idealism and concurrentism.
\end{abstract}

\section{Berkeley, Human Agency and Divine Concurrentism ${ }^{1}$}

\author{
Jeffrey K. McDonough \\ Department of Philosophy \\ Harvard University \\ jkmcdon@,fas.harvard.edu
}

Introduction

Berkeley clearly, confidently, and consistently maintains that only spirits can be causes. In doing so, he would appear to distinguish God and finite souls from ideas and "bodies," with the former falling on the active side, and the latter on the passive side of the traditional, if slippery, active-passive distinction. ${ }^{2,3}$ Nonetheless, Berkeley's commentators have found his characterization of finite souls as active deeply problematic on both textual and philosophical grounds. Many have consequently struggled to interpret him either as a closet Malbranchian 
occasionalist, ${ }^{4}$ or resigned themselves to reading him as philosophically muddled, ${ }^{5}$ or even grossly inconsistent, ${ }^{6}$ on the issue of human agency.

In spite of the difficulties that contemporary philosophers have had in making reasonable sense of Berkeley's position, I would like to suggest that there is a rather straightforward reading of his view that is historically sensitive, fits squarely with his texts, and is philosophically wellmotivated. The first section of what follows briefly revisits three options concerning the relationship between human and divine agency available to theistically minded philosophers in the medieval and early modern eras. The second argues that of those three views only the position of concurrentism is consistent with Berkeley's texts. The third section explores Berkeley's reasons for adopting concurrentism, especially as opposed to occasionalism, by highlighting three motivating considerations drawn from his larger philosophical system. Finally, the fourth section attempts to flesh out Berkeley's understanding of human activity by looking at how we might understand his claim that we move our legs ourselves in light of his commitment to both idealism and concurrentism.

\section{Concurrentism, Occasionalism, and Mere Conservationism}

For theistic philosophers of the later medieval and early modern periods, discussions of human agency took place against a background of views concerning the general relationship between God's ongoing activity and the activity, if any, of his creatures. A fundamental tension bedeviled attempts to find a suitable balance between divine and creaturely contributions. In general, piety pulled the faithful in the direction of maximizing God's activity even at the cost of construing the contribution of finite creatures in ever more passive terms. The felt need to 
preserve the independence of creatures and provide robust grounds for explanations in natural philosophy, however, pulled in the opposite direction, often encouraging even the most devout to reserve at least some active powers for created beings. Three main views-in countless variations - emerged in response to this fundamental tension, each suggesting a different balance between divine and creaturely activity. ${ }^{7}$

Divine concurrentism represents a relatively moderate solution to the fundamental problem of how to distribute the activity of the world between God and his creatures. At the heart of concurrentism can be found three foundational commitments:

First, concurrentists maintain that God's activity is not merely required to create the world but also to conserve it in its existence. Indeed, they generally adopt the traditional view that God works through the very same activity in both creating and conserving the world. ${ }^{8}$ It is perhaps worth noting that the doctrine of divine conservation, like the doctrine of creation itself, was in no way unique to divine concurrentism, and could be denied in earlier eras only by those willing to positively invite charges of heresy.

Second, concurrentists insist that creatures are endowed with genuine active and passive powers, and that they exercise their powers in ordinary causal interactions.

Concurrentists thus explicitly commit themselves to the view that creatures make genuine causal contributions to the non-miraculous unfolding of events in nature. In this way they hope to provide the causal grounds that they take to be necessary for natural science and human responsibility. 
Third, and most distinctively, concurrentists maintain that although creatures are endowed with genuine causal powers, no creaturely causal power could be efficacious in bringing about its appropriate effects without God's active general assistance, or "concurrence." Consequently, concurrentists maintain, for example, that when my hands are placed near a fire they are warmed not simply by the causal powers of the fire, but by the causal powers of the fire working in concert with God's active assistance.

Although often overlooked today, concurrentism enjoyed the status of a default position for many in the medieval and early modern periods. It could count among its defenders Albert the Great and Thomas Aquinas in the thirteenth century, ${ }^{9}$ Luis de Molina and Francisco Suarez in the sixteenth, ${ }^{10}$ and Robert Boyle and Gottfried Leibniz in the seventeenth. ${ }^{11}$ In spite of its impressive lineage, however, concurrentism did not, of course, enjoy universal assent. It was attacked on both sides, with "mere conservationists" arguing that it assigns too large a role to God's activity in the causal unfolding of the world, and occasionalists arguing that it assigns too small a role to God's activity. Both of these alternative views can be seen as abandoning a foundational commitment of concurrentism.

Mere conservationism embraces a distribution of causal activity that is tilted somewhat more in favor of created agents than is suggested by concurrentism. In essentials, it can be arrived at by adopting the first two tenets listed above, while denying the third. Thus mere conservationists agree that God's activity is necessary for both the creation and conservation of finite beings. Furthermore they agree that God creates and conserves creatures complete with their own active powers and that those powers are exercised in ordinary causal interactions. What mere conservationists deny is that, having been created and conserved, creatures require any further assistance on God's part in order for them to successfully bring about their ordinary 
effects. Thus, for example, according to mere conservationists, while the continued existence of the fire and my hands presupposes God's conserving activity, the fire alone is the immediate active cause of the warming of my hands.

In spite of its elegance and contemporary appeal, mere conservationism has historically attracted few supporters. ${ }^{12}$ It was assailed by its opponents on broadly philosophical grounds as being at root incoherent. Thus, for example, Suarez argues that mere conservationism would commit one to an untenable position according to which: (i) The power by which God creates creatures and their powers is equivalent to the power by which he conserves them; (ii) God's activity is necessary for the conservation of creatures and their powers; but (iii) God's activity is not necessary for the production, or creation, of the effects of secondary causes. In short, Suarez thus objects that the mere conservationist must paradoxically hold that although God creates and sustains through one and the same activity, God's activity is required for the maintenance, but not the creation, of creaturely effects. ${ }^{13}$

Mere conservationism was also attacked by its opponents on more purely theological grounds. Perhaps the most crucial objection raised was simply that a greater role could be assigned to God's activity in the causal unfolding of the world, and therefore that piety demands that such a greater role actually be assigned. ${ }^{14}$ To this rather bald argument could be added considerably more subtle theological considerations. It was objected, for example, that mere conservationism runs into trouble in connection with what were known as contra naturam miracles. In his De potentia Aquinas had claimed that such miracles occur "when there remains in nature a disposition that is contrary to the effect which God produces, as when he kept the young men unharmed in the furnace even though the power to incinerate them remained in the fire, and as when the waters of Jordan stood still even though gravity remained in them."15 
Picking up on Aquinas's definition, and often using his very examples, concurrentists argued that mere conservationists were committed to the impious view that in performing contra naturam miracles God would have to actively oppose his own creatures rather than merely withhold his assistance. It was better to maintain, they claimed, that God for example prevented the young men from being consumed by the flames of Nebuchadnezzar's furnace by withholding his concurrence, rather than by actively opposing the natural powers of the fire itself. ${ }^{16}$

Occasionalism, lying at the opposite end of the spectrum from mere conservationism, would tip the distribution of activity between God and his creatures completely in favor of the divine. If mere conservationism can be thought of as the result of denying the third principle of concurrentism, occasionalism can be thought of as the result of denying its second principle. Thus occasionalists maintain that God not only creates and conserves the world, but is, indeed, its only genuine causal power. ${ }^{17}$ Apparent secondary causes serve merely as the occasions of God's causal activity. Thus, for example, occasionalists maintain that the fire does not warm my hands in virtue of its own active powers, but rather serves merely as the occasional "cause" of God's directly warming my hands when they are placed near it.

Although treated dismissively by Aquinas and many later scholastics, ${ }^{18}$ occasionalism received a significant boost in the early modern period from the Cartesian attack on scholastic ontology and natural philosophy as well as from its sophisticated defense by Nicholas Malebranche. ${ }^{19}$ Nonetheless it would be a mistake to suppose that occasionalism supplanted concurrentism as the default view among philosophers outside of Cartesian circles. To many, the suggestion that God alone actively brings about every effect in the natural world seemed simply fantastic and smacked of the perpetually miraculous. To this sense of general disbelief were added more focused criticisms that called into question the philosophical and theological merits 
of occasionalist doctrines especially as when applied to the case of finite minds or spirits. Thus Leibniz, for example, argues that activity is an essential characteristic of substance in general, and therefore without activity finite spirits would fail to qualify as substances in their own right, and would collapse into mere modifications of God. ${ }^{20}$ To this reductio ad Spinozism, Leibniz further argues that denying activity to finite minds would undermine their claim to being genuine agents endowed with free will, and thus ultimately would undermine the possibility of their being responsible for their own actions and the project of theodicy itself. ${ }^{21}$

More could, of course, be said about the relative merits and deficiencies of concurrentism, conservationism, and occasionalism. What is important for our purposes, however, is simply to recall the background against which Berkeley's own thinking about human activity takes place, and to recognize that although concurrentism might often be overlooked as a possible position today, no one in Berkeley's day could have failed to recognize it as a serious option. Indeed, in the next section, I'd like to suggest not only that Berkeley's texts clearly indicate his awareness of concurrentism as a possible position, but also that reading him as a concurrentist provides the most coherent understanding of the various things he says about human agency.

\section{Concurrentism: The Textual Case}

The first difficulty one faces in coming to grips with Berkeley's position on human agency is simply reconciling the seemingly contradictory pronouncements he makes on the topic. An important clue in addressing this challenge can be found in a number of passages in which Berkeley clearly indicates that he is — at the very least - well aware of concurrentism as a 
possible position to take with respect to secondary causation. ${ }^{22}$ The most striking of those passages occurs at Principles 145, where Berkeley tells us point blank, "I perceive several motions, changes, and combinations of ideas, that inform me there are certain particular agents like my self, which accompany them, and concur in their production" (emphasis added). As is clear from the larger context - the next section emphasizes that God alone is responsible for "the far greater part of the ideas or sensations perceived by us"- the concurrence Berkeley has in mind here is a cooperative action produced by God working in concert with finite spirits. The passage thus, at a minimum, provides us with a first bit of textual evidence that Berkeley was well aware of the concurrentist alternative to mere conservationism and occasionalism.

Another relevant passage occurs earlier in the same work in the context of Berkeley's rejection of the view that non-spirits might be genuine secondary causes. Having argued that "the connexion of ideas does not imply the relation of cause and effect, but only a mark or sign with the thing signified," he tells us at Principles 66:

$<$ ext $>$

Hence it is evident, that those things which under the notion of a cause co-operating or concurring to the production of effects, are altogether inexplicable, and run us into great absurdities, may be very naturally explained, and have a proper and obvious use assigned them, when they are considered only as marks or signs for our information. (emphasis added)

$</$ ext $>$

In this passage Berkeley is first and foremost concerned with establishing a negative point, namely, that ideas are merely signs of other ideas, and not—as we might have otherwise supposed - concurrent causes of other ideas. While the Berkeleyan thesis that idea-idea 
causation is always occasional is beside the point for our immediate concerns, it is nonetheless telling that the position that Berkeley finds it most natural to resist here is one according to which non-spirits are concurrent causes of their effects. Once again, whatever else one might make of the passage, it thus at least indicates that Berkeley was well aware of concurrentism as a standard view to be adopted or rejected.

A final passage worth calling attention to is to be found in the Second Dialogue, where Hylas - providing opposition to Berkeley's own view — attempts to clarify his position on the causal activity of matter, stating:

$<\mathrm{ext}>$

But I am afraid you do not thoroughly comprehend my meaning. I would by no means be thought to deny that God or an Infinite Spirit is the supreme cause of all things. All I contend for, is, that subordinate to the supreme agent there is a cause of a limited and inferior nature, which concurs in the production of our ideas, not by any act of will or spiritual efficiency, but by that kind of action which belongs to matter, viz. motion. (Dialogues, 2:217)

$</$ ext $>$

Philonous, speaking for Berkeley, is short in his reply, retorting to Hylas "you are at every turn relapsing into your old exploded conceit, of a moveable and consequently an extended substance existing without the mind" (Dialogues, 2:217). Berkeley's leading point is thus once again negative, and directed at the very possibility of non-spirit causes. In Hylas's remarks, however, we nonetheless see once again clear positive evidence of Berkeley's awareness of concurrentism as a standard available position to take with respect to creaturely causation. 
Berkeley's awareness of concurrentism as a live option with respect to creaturely causation provides an important clue for understanding his more famous remarks on human agency. One striking passage that has figured heavily in recent treatments of Berkeley's position is drawn from his private notebooks:

$<\operatorname{ext}>$

Strange impotence of men. Man without God. Wretcheder than a stone or tree, he having onely the power to be miserable by his unperformed wills, these having no power at all. $(N, 107)$

$<\mathrm{ext}>$

This dramatic passage has often been invoked in support of attributing occasionalism to Berkeley since it so clearly emphasizes that humans would be impotent without God's activity. In fact, however, the passage is neutral between either an occasionalist or a concurrentist reading of Berkeley since both occasionalists and concurrentists agree that God's active assistance is a necessary condition for secondary causes to succeed in bringing about their natural effects.

While the wretcheder-than-a-stone passage thus fails to support occasionalism over concurrentism, it does help to rule out Berkeley's adoption of mere conservationism. Recall that the mere conservationist holds that the ordinary activities of secondary causes are beholden to God's assistance only insofar as God is needed to preserve creatures in being. The wretchederthan-a-stone passage, however, commits Berkeley to a stronger position since it implies that people would be wretched without God's help, not because they would cease to exist, but because while still existing their wills would cease to be efficacious. (Indeed, non-existing people could hardly be thought to be wretched by dint of their impotent wills.) This bit of textual evidence gains further support from Berkeley's exchange of letters with Samuel Johnson. 
There Berkeley summarily dismisses the position of the chief proponent of mere conservationism in the middle ages, Durandus de St. Pourçain, following the familiar concurrentist strategy of implying that his view collapses into deism (Works, 2:280). ${ }^{23}$ Viewed in their appropriate historical contexts, these texts therefore give good evidence that—as we might have expected anyway—Berkeley had no truck with mere conservationism with respect to finite wills.

Another short, but striking passage, from Berkeley's notebooks has also figured prominently in the interpretation of his position on human agency: $<\mathrm{ext}>$

We move our Legs our selves. 'tis we that will their movement. Herein I differ from Malbranch. $(N, 548)$

$</$ ext $>$

In light of the often assumed occasionalism of the wretcheder-than-a-stone passage, contemporary commentators have typically responded to this seemingly unequivocal statement of anti-occasionalism in either of two ways. On the one hand, there are those who have downplayed its significance in hopes of nonetheless reading Berkeley as a committed occasionalist. Thus, for example, George Pitcher after citing the move-our-legs-ourselves passage and conceding its anti-occasionalism, nonetheless attempts to diffuse its importance by insisting that in "the great published works, however, things are different." ${ }^{, 4}$ On the other hand, there are those who have emphasized the move-our-legs-ourselves passage and its apparent inconsistency with the wretcheder-than-a-stone passage in arguing that Berkeley's position on human agency is at root incoherent. Thus, for example, Nicholas Jolley, after citing both passages, remarks apropos of the latter that "Berkeley's departure from strict occasionalism is 
something of a puzzle, for in terms of philosophical consistency, it seems to represent a change for the worse." 25

Although charitably intentioned, the attempt to treat the move-our-legs-ourselves passage as a passing anomaly faces overwhelming textual opposition. Berkeley repeatedly insists not only in the notebooks, but also in "the great published works," that human wills are genuinely active secondary causes. Thus, for example, in the Principles, Berkeley, in contrasting the activity of the human will in conjuring up its own thoughts with the mind's passive reception of sensory ideas, writes:

$<\mathrm{ext}>$

I find I can excite ideas in my mind at pleasure, and vary and shift the scene as oft as I think fit. It is no more than willing, and straightway this or that idea arises in my fancy: and by the same power it is obliterated, and makes way for another. This making and unmaking of ideas doth very properly denominate the mind active. Thus much is certain, and grounded on experience. (Principles, 1:28)

$</$ ext $>$

The activity of the human will is likewise asserted in The Dialogues, as for example in the following passage where Berkeley, speaking through Philonous, subtly distinguishes between our activity with respect to the movements of our bodies and our passivity with respect to the sensory perceptions which we experience as a result of those movements: $<\operatorname{ext}>$

The mind therefore is to be accounted active in its perceptions, so far forth as volition is included in them. ... In plucking this flower, I am active, because I do it by the motion of my hand, which was consequent upon my volition; so likewise in applying it to my 
nose....I act too in drawing the air through my nose; because my breathing so rather than otherwise, is the effect of my volition. But neither can this be called smelling: for if it were, I should smell every time I breathed in that manner. ... Smelling then is somewhat consequent to all this.... Whatever more there is, as that I perceive such a particular smell or any smell at all, this is independent of my will, and therein I am altogether passive. (Dialogues, 1:196)

$</$ ext $>$

The move-our-legs-ourselves passage is admittedly remarkable in the crispness of its rejection of occasionalism as well as in the way in which it explicitly ties that rejection to Malebranche by name. ${ }^{26}$ The stance it expresses, however, is hardly unique either to it, or to the Notebooks. ${ }^{27}$ For better or for worse, Berkeley wishes to distance his own view from occasionalism, and any interpretation that aims to account for what Berkeley actually said cannot afford to simply ignore the thick streak of anti-occasionalism in his writings.

Recent interpretations that attribute outright inconsistency to Berkeley are thus a step in the right direction insofar as they take seriously both sides of his complex attitude towards human activity. They are overly hasty, however, in assuming that the passages in which Berkeley is at pains to emphasize our dependence on God's assistance are in insurmountable tension with the equally important passages in which he takes care to emphasize our causal contribution to our own actions. Taking the wretcheder-than-a-stone passage as representative of the former set of texts, we have seen that while it is inconsistent with mere conservationism, it is nonetheless perfectly consistent with either an occasionalist or a concurrentist view of human agency. Taking the move-our-legs ourselves passage as representative of the latter set of texts, we can now see that while it is inconsistent with occasionalism, it is nonetheless perfectly 
consistent with either concurrentism or mere conservationism. A consistent interpretation of Berkeley's texts is thus readily available if we understand him as belonging to the hoary tradition of divine concurrentism. Texts such as the wretcheder-than-a-stone passage may thus be recognized as asserting the concurrentist commitment to God's active assistance being a necessary condition for the efficaciousness of creaturely activity, while texts such as the moveour-legs-ourselves passage may be understood as asserting the concurrentist commitment to the genuine causal contribution of secondary agents. There is no need to attribute inconsistency, or even vacillation, to Berkeley's views on the activity of finite minds.

\section{Concurrentism: The Philosophical Case}

If the first difficulty in coming to grips with Berkeley's account of human agency is finding a coherent interpretation of his texts, the second challenge has traditionally been to understand why he should have been drawn — perhaps reluctantly— to the position he adopts. This second challenge, I think, loses some of its urgency once it is recognized that Berkeley held consistently to a concurrentist position. Certainly, if the reading offered above is correct, no special account can be demanded for why Berkeley changed his mind, or why he was pulled in opposite directions, with respect to the activity of the will. Nor is there anything especially puzzling about Berkeley's finding concurrentism an attractive position. Presumably many of the same reasons that motivated generations of theistically minded philosophers in the medieval and early modern eras to adopt concurrentism resonated with Berkeley as well. Nonetheless, given the contemporary tendency to suppose that Berkeley should have embraced occasionalism with respect to finite minds, it might be helpful to underscore three considerations drawn from his 
larger philosophical system that give him particular reasons for favoring concurrentism over occasionalism. Highlighting those philosophical motivations should serve to further support the case for Berkeley's commitment to concurrentism, and help to expose how deeply that commitment is enmeshed in his general metaphysics and epistemology.

The first such consideration arises immediately from what might be called "Berkeley's Dualism." ${ }^{28}$ Berkeley takes it as a non-negotiable truth that the distinction between activity and passivity coincides with the distinction between spirits and ideas. As is perhaps not inappropriate for such a foundational commitment, he insists that both the connection between spirit and activity as well as the connection between idea and passivity are readily apparent upon reflection. Thus, for example, in the Dialogues, he suggests that it is simply inconceivable that anything other than a spirit might be an active cause of ideas. With Philonous as his spokesman, he announces "I desire to know in the first place, whether ... you can conceive any action besides volition: and ... lastly, whether having considered the premises, you do not perceive that to suppose any efficient or active cause of our ideas other than spirit, is highly absurd and unreasonable?" (Dialogues, 2:217; see also N, 155, 499, 499a, 850). The correlative connection is insisted upon with no less conviction. Thus, for example, in the Principles, Berkeley announces that "A little attention will discover to us that the very being of an idea implies passiveness and inertness in it, insomuch that it is impossible for an idea to do any thing, or, strictly speaking, to be the cause of any thing" (Principles, 25).

Beyond these appeals to brute intuition, Berkeley also maintains that the alignment of the active-passive distinction and the spirit-idea distinction can be established on experiential grounds. In Alciphron, Berkeley insists "though you should tell me that man is inactive, and that the sensible objects act upon him, yet my own experience assures me of the contrary. I know I act 
..." (7:19, emphasis added). Experience, Berkeley maintains, is likewise sufficient to establish the connection between ideas on the one hand and passivity on the other. At Principles 25, he reports:

$<\mathrm{ext}>$

All our ideas, sensations, or the things which we perceive, by whatsoever names they may be distinguished, are visibly inactive, there is nothing of power or agency included in them. So that one idea or object of thought cannot produce, or make any alteration in another. To be satisfied of the truth of this, there is nothing else requisite but a bare observation of our ideas. For since they and every part of them exist only in the mind, it follows that there is nothing in them but what is perceived. But whoever shall attend to his ideas, whether of sense or reflexion, will not perceive in them any power or activity; there is therefore no such thing contained in them.

$</$ ext $>$

By drawing either on reflection or experience, Berkeley thus thinks we can establish beyond question that all spirits must be active and all ideas essentially passive. The divide between active spirits and passive ideas in this way constitutes a fundamental plank in Berkeley's groundfloor metaphysics. It is a dualistic division that is every bit as deep in his system as the distinction between mind and body is in Descartes's. ${ }^{29}$

It must be admitted that it is somewhat difficult today to feel the force of Berkeley's arguments for his own brand of dualism, or for that matter to even evaluate their strength and cogency. Certainly the intuition that only spirits can be active will be absent for many contemporary philosophers, and one might well be at a loss as to how to even begin to recreate the experiences to which Berkeley appeals. ${ }^{30}$ The tenability of Berkeley's dualism, however, is 
less important for our purposes than is his staunch commitment to it. For given that commitment, it is rather easy to see why he should have favored a concurrentist account of finite spirits over an occasionalist account. Put positively, by treating finite spirits as concurrent causes Berkeley can safely place human souls on the side of God and the angels as genuine active beings and distinguish them from purely passive ideas. ${ }^{31}$ Put negatively, given his dualism, an occasionalist account of finite spirits would threaten to group human souls together with passive ideas, and oppose them to God — the only genuinely active being in the world. Berkeley's dualism thus provides him with a powerful reason for preferring a concurrentist account of finite minds to an occasionalist account.

The second consideration is now close to hand. Like many philosophers before him, Berkeley maintains that resemblance, or similarity, is a necessary condition for representation (Principles, 140). This not uncommon semantic thesis, when combined with Berkeley's dualism, leads him to the surprising conclusion that, strictly speaking, ${ }^{32}$ our ideas can in no way represent spirits:

$<\mathrm{ext}>$

By the word spirit we mean only that which thinks, wills, and perceives; this, and this alone, constitutes the signification of that term. If therefore it is impossible that any degree of those powers should be represented in an idea, it is evident there can be no idea of a spirit. (Principles, 138; see also Principles, 27)

$</$ ext $>$

Berkeley's views on representation, when paired with his fundamental metaphysics, thus threaten a kind of semantic skepticism with respect to other spirits, whether finite or divine. If all ideas are passive, all spirits are active, and nothing passive can represent anything active, then 
it follows that by using our ideas we cannot even so much as think about other spirits. Indeed, even more strikingly, it follows that we cannot even use ideas to think about our own fundamental natures insofar as they surpass a mere collection of ideas.

Berkeley's solution to this impasse rests squarely on his famous — or perhaps notoriousdoctrine of notions. Very briefly, Berkeley holds that we enjoy two modes of experience: one corresponding to sensory perception, one corresponding to reflection on the mind's own operations. ${ }^{33}$ Whereas the first mode of experience yields passive ideas capable of representing other ideas, the second mode yields notions capable of representing active beings. In keeping with his views on representation, Berkeley maintains that notions draw their capacity for representing active beings from the fact that they are derived from reflection on our own active natures. He thus maintains that "we know other spirits by means of our own soul, which in that sense is the image or idea of them," and that "all the notion I have of God, is obtained by reflecting on my own soul... [and] I have therefore, though not an inactive idea, yet in my self some sort of an active thinking image of the Deity" (Principles, 140; Dialogues, 3:231-232). Semantic skepticism of active natures is thus avoided through the doctrine of notions. Although no passive idea, according to Berkeley, could possibly represent an active spirit, a notion that is derived from an active nature is capable of serving as an object of thought about active natures.

While Berkeley's doctrine of notions has many subtle consequences for his general epistemology, its implications for our present concerns are relatively straightforward. Pushed towards semantic skepticism with respect to spirits by his commitment to dualism and a resemblance theory of representation, Berkeley suggests that reflection on our own active natures provides us with the resources to form thoughts about active natures more generally. But crucial to this maneuver, of course, is the supposition that our natures are themselves active! If I, for 
example, were not myself a genuine, active, secondary cause, Berkeley maintains, then I could not even form a thought about other finite spirits, or more importantly, about God himself. Thus insofar as concurrentism allows Berkeley to treat created sprits-including ourselves-as genuine, active, secondary causes, rather than as the mere occasional causes of God's lone activity, his semantic views provide him with another significant reason for preferring concurrentism with respect to finite minds over occasionalism.

A third consideration, although it provides perhaps a less decisive reason for Berkeley's favoring concurrentism over occasionalism, nonetheless helps to bring out how deeply concurrentist thinking is woven into Berkeley's larger philosophical outlook. Even supposing that Berkeley's appeal to notions provides him with sufficient resources for resisting semantic skepticism with respect to spirits, a further worry remains concerning our knowledge of spirits. Berkeley maintains that the threat of epistemological skepticism is easily turned away in the case of self-knowledge and knowledge of the divine. He not implausibly maintains that each of us enjoys an immediate, non-inferential awareness of our own existence, which serves as an unshakeable foundation for self-knowledge (see, for example, Principles, 89). He further holds that we may justifiably infer the existence of God from the "constant regularity, order, and concatenation of natural things" as well as from the fact that we are subject to "ideas or sensations perceived by us, [but that] are not produced by, or dependent on the wills of men" (Principles, 146). In this way, our knowledge of God's existence is likewise supposed to be put on firm epistemological foundations.

The case of other finite minds, however, so far remains precarious. Berkeley maintains that we "have neither an immediate evidence nor a demonstrative knowledge of the existence of other finite spirits" (Dialogues, 3:233; see also Principles, 147 and Alciphron, 4:5). We are thus 
forced to infer their existence from the perceptions of which we do have an immediate awareness. But how could such ideas ever give us evidence of a world of finite beings independent of ourselves? Berkeley's clever response in effect puts a novel twist on the problem of evil: our experience of some irregularities and imperfections in the flow of ideas can only be accounted for by supposing that God accommodates himself to the wills of imperfect finite minds. Lorne Falkenstein elegantly puts the argument as follows: $<\mathrm{ext}>$

[A]mong our ideas of reality there are some, those of the motions of animate bodies, which exhibit a degree of irregularity, inconstancy of purpose, greed, stupidity, and sheer perversity which is simply inconsistent with the notion that these ideas are produced by a wise and benevolent being. One plausible way to deal with these phenomena is to postulate that there exist certain other spirits whose wills the divine spirit is disposed to indulge when moving animate bodies.... It is in this way that we deduce the existence of other minds "from their operations, or the ideas by them excited in us."

$</$ ext $>$

Considered in isolation Berkeley's solution to the problem of other (finite) minds appears to be consistent with either a concurrentist or an occasionalist treatment of finite souls. Certain imperfections in the pattern of ideas could arise either because God accommodates himself to concurrent causes or to occasional causes. Taken by itself, Berkeley's solution to the problem of other minds therefore cannot be counted as a compelling reason for embracing one of these doctrines over the other. Nonetheless, an important motivation emerges when Berkeley's solution is considered in conjunction with his views on human responsibility. 
In the Dialogues, Berkeley has Philonous insist against Hylas that genuine activity is a necessary but not sufficient condition for responsibility (Dialogues, 3:236-237). The thesis that genuine agency is essential to moral responsibility is stated even more explicitly in Alciphron: $<$ ext $>$

It should seem, therefore, that, in the ordinary commerce of mankind, any person is esteemed accountable simply as he is an agent. And, though you should tell me that man is inactive, and that the sensible objects act upon him, yet my own experience assures me of the contrary. I know I act, and what I act I am accountable for. And, if this be true, the foundation of religion and morality remains unshaken. (7:19)

$</$ ext $>$

Through his account of moral responsibility Berkeley's concurrentism gets woven into his solution to the problem of other (finite) minds. Berkeley must concede that God could be the sole cause of all of our perceptions. Nonetheless, he insists that at least some of the imperfections we experience in the flow of ideas cannot be morally attributed to God. Those imperfections thus give us grounds for postulating other beings that are to be held morally accountable for certain sub-optimalities in the world. But not just any beings will do here according to Berkeley. For such beings to be morally responsible, they must be genuine finite agents that enjoy "the use of limited powers ... immediately under the direction of their own wills, which is sufficient to entitle them to all the guilt of their actions" (Dialogues, 3:237). In short, the relevant imperfections of the world must have as their source genuine secondary causes, not mere occasions for God's activity. It is this further element that underpins Berkeley's claim (noted above) that "I perceive several motions, changes, and combinations of 
ideas, that inform me there are certain particular agents like my self, which accompany them, and concur in their production" (Principles, 145, emphasis added; see also Principles, 148).

\section{Moving Our Legs Ourselves}

The textual and philosophical considerations adduced thus far suggest that Berkeley must break with strict occasionalism by assigning at least some genuine activity to finite minds. They do not, however, specify how far that activity must extend. For all that has been argued, Berkeley could have adopted a position just short of strict occasionalism, indeed, a position that might appropriately be called "almost-occasionalism." According to such a view the activity of finite minds would consist merely in their being immediate concurrent causes of their own volitions, perhaps together with ideas of imagination, with those volitions and imaginations in turn serving as occasional causes for God's direct causal intervention in bringing about whatever consequences might follow from them. Such a position would represent a minimal model of human agency consistent with Berkeley's insistence on human agents being genuine secondary causes; it would differ from a letter-of-the-law occasionalism only in its explicit acknowledgement of the causal powers agents have in virtue of being able to form volitions and conjure fantasies.

Although Berkeley certainly could have adopted a position such as almost-occasionalism, there are, as we have seen, numerous passages which suggest that he is inclined towards a more ambitious picture of human agency, including those in which he claims that "we move our legs ourselves;" that "In plucking this flower, I am active, because I do it by the motion of my hand;" that "I never use an instrument to move my finger, because it is ... an effect immediately 
depending on the will ...;" that we have learned through experience that in thinking things there is a "power of moving bodies ... since our mind at will can stir and stay the movements of our limbs" (N, 548; Dialogues, 1:196; Dialogues, 2:218f; De motu, 25). Having focused thus far on placing Berkeley in the concurrentist tradition on the basis of some otherwise puzzling texts and the philosophical demands of his system, we might in this last section explore-perhaps a bit more speculatively—whether Berkeley is entitled to suggest that we may enjoy an immediate and direct causal influence over not only our volitions and imaginings, but also over our bodies and limbs. Towards that end, let us consider four prima facie worries that might be thought to stand in the way of Berkeley's embracing a more ambitious model of human agency than is suggested by almost-occasionalism.

(1) The traditional concurrentist framework for thinking about creaturely activity was hammered out by later scholastics in the context of an ontology very different from Berkeley's idealism. A first worry, or really source of worries, therefore arises concerning the general compatibility of that framework with Berkeley's metaphysics. Although this is not the place to fret over the finer details of traditional concurrentism and potential objections to it, it might nonetheless be helpful to show, in at least a preliminary way, how Berkeley could fairly assume three of the most central theses of his scholastic predecessors. Doing so should help to show that nothing about the conjunction of concurrentism and idealism per se forces Berkeley towards an almost-occasionalist model of human agency. ${ }^{35}$

First, later scholastics in the concurrentist tradition insisted on the importance of distinguishing —at least conceptually — between the order of creation-conservation and the order of concurrence. As noted in the opening section, they traditionally held that God brings creation into being ex nihilo, and—barring annihilation— preserves that original being per se. ${ }^{36}$ This act 
of creation-conservation was viewed as being in some sense prior-and as it were orthogonalto the order of concurrence through which God lends his active assistance to the causal powers of created substances in bringing about their ordinary effects. For the scholastics, my creation and conservation are thus treated as necessary conditions for my having a nature capable of contributing to the movement of my legs, while God's concurrence is understood as an additional or further necessary condition for my causal powers bringing about their ordinary effects. Whether or not one is sympathetic with these standard theological distinctions, it should be granted that they are no less tenable in the context of Berkeley's idealism. ${ }^{37}$ Berkeley may, with as much right as his scholastic predecessors, insist that God's creation and conservation of finite minds and their perceptions - whether those perceptions are treated as mere modifications or as reified entities - are necessary conditions for the causal activity of creatures within the order of nature, and that God's concurrence is to be thought of as an additional or further act through which God contributes his active assistance to the causal powers of created minds.

Second, turning more fully to the order of nature, and thus to the order of concurrence itself, later scholastics insisted that we should think of God's concurrence with a finite agent as producing a unified effect through a unified action. For if the effect were somehow divided or conjunctive, the secondary agent might just as well be thought to be a non-concurrent cause of one of the conjuncts and an occasional cause of the other. Thus, to take a facile example, it would be obviously foolish to suggest that God and I concur in moving my legs by me moving my left leg and by God moving my right leg. Similarly, the ways in which two agents might be said to bring about a unified effect through distinct actions seem in general to be unsuitable as accounts of the cooperative action between God and his creatures. Thus, to take another easy example, it would again be foolish to suggest that God and I bring about the movement of my 
legs by causally overdetermining their motion. For in that case, it would follow that my action by itself would be causally sufficient for bringing about their movement, contrary to the central thesis of concurrentism, namely, that no finite creature is able bring about its customary effects without God's active assistance within the order of nature. Although on an ambitious model, Berkeley would have to insist that the bodily effects of creatures are typically alternations in the flow of perceptions rather than changes in a material world, nothing about this ontological shift seems to preclude his agreeing that God and creatures act together in bringing about unified alterations through unified actions.

Finally, later scholastic proponents of concurrentism maintained that—even where God and I act through a single action in bringing about a unified effect-it is still possible to conceptually trace some aspects of the production of that effect to my nature and some aspects to God's nature or will. Such a conceptual tracing, or distinguishing, was held to be theologically essential in order to explain why, for example, although God and I bring about a unified sinful effect through a single action, the responsibility for the effect's sinfulness rests with me and not with God. One common way of developing this doctrine was to hold that while God's creation, conservation, and concurrence are necessary for the very possibility of the production of creaturely effects, his general concurrence is nonetheless tailored to the demands of natural powers and the choices of free agents. Thus, the fact that a particular effect is (say) a heating rather than a cooling may be attributed to the nature of the concurring fire rather than to God (since if God had concurred with some water, a cooling would have been produced instead). ${ }^{38}$ Likewise, the fact that a particular effect is an instance of sinning rather than an instance of virtuous behavior is to be traced back to the will of a finite agent rather than to God (since if God had concurred with a virtuous agent, an instance of virtuous behavior would have been produced 
instead). Once again, although Berkeley would have to understand the ontological nature of the relevant effects quite differently, nothing about his idealism precludes him from taking advantage of the crucial scholastic strategy of drawing a conceptual distinction between divine and creaturely causal contributions.

(2) Even if it is granted that Berkeley could adopt much of the scholastic framework for thinking about concurrent agency, and avail himself of already developed scholastic responses to many familiar difficulties, one might still suppose that the distinction within his system between what he often calls "real things" and "chimeras," and what we might call "objective" and "subjective" experiences, precludes his adopting an ambitious model of human agency. The worry here is rooted in the thought that if Berkeley grants that we may directly influence the collections of perceptions constituting our bodies, he will not be able to distinguish between objective and subjective experiences in terms of involuntary and voluntary control. For, on an ambitious picture, my legs (for example) would seem to be both responsive to my will and belong to the objective realm. Therefore, if it is supposed that "involuntariness must be a necessary condition of the reality of Berkeley's 'real' ideas," ${ }^{39}$ then a robust account of his claim that "we move our legs ourselves" would commit him to either denying the reality of our bodies, or land him straightaway in a contradiction.

Although the objection is a serious one, there is a readily available solution: deny the assumption that total involuntariness is either a sufficient or a necessary condition for an experience's being objective. That it should not be reckoned a sufficient condition should be clear from our willingness to count even involuntary illusions, hallucinations, and dreams as subjective experiences. There is no reason to suppose that the earthquake experience I had last night while dreaming should be deemed objective just in virtue of the fact that it was 
involuntary. That it should not be counted as a necessary condition gains force not only from the ways in which we standardly interpret experiences of our own bodies, but also from our ability to indirectly influence our experience of the world through the control we enjoy over our bodies, as well as by our ability to focus and direct our attention. The fact that I can typically determine whether I see my own hand as open or closed (since I'm the one who typically opens and closes it), that I can avoid seeing the tree by shutting my eyes, and that I can direct my attention to the sound of the birds and away from the noise of the traffic does not require me to suppose that those experiences are merely subjective. Rather than hold that involuntariness is either a necessary or a sufficient condition for objective experience, it would thus seem more reasonable to treat responsiveness to our volitions as one factor among many upon which we may draw in distinguishing between objective and subjective experiences.

Such a response is, I think, not only a perfectly good answer that is available to Berkeley, but in all likelihood his own considered answer as well. He repeatedly indicates that we enjoy at least an indirect control over many of our objective sensory experiences in virtue of our ability to influence our own bodies. Thus, for example, in the Notebooks he writes, "There is somewhat active in most perceptions i.e. such as ensue upon our Volitions, such as we can prevent \& stop v.g I turn my eyes towards the Sun I open them all this is active" (N, 672a; see also Dialogues, 1:196). Likewise, even in his canonical statements of the distinction between subjective and objective experience, Berkeley implies only that "the ideas perceived by sense, that is real things ... have not a like dependence on our will," and are at any rate less "dim, irregular and confused" than "ideas formed by the imagination" (Dialogues, 3:235, italics added). Indeed, far from resting on a simple distinction based on voluntariness as a necessary and sufficient condition, Berkeley smartly insists that "by whatever method you [i.e. the materialist] distinguish 
things from chimeras on your own scheme, the same, it is evident, will hold also upon mine. For it must be, I presume, by some perceived difference, and I am not for depriving you of any one thing that you perceive. (Dialogues, 3:235; see also Principles, 29-34). In letting the distinction between "real things" and "chimeras" rest on a broad range of defeasible criteria Berkeley leaves open the possibility that we may have a direct causal influence even over aspects of objective reality, and in doing so effectively dissolves what would otherwise be an embarrassing objection to an ambitious model of human agency.

(3) A further worry that might be thought to block the possibility of Berkeley's embracing an ambitious view of human agency arises in connection with his understanding of the active-passive distinction. According to one tempting view, Berkeley is committed to our being wholly active with respect to our ideas of imagination and wholly passive with respect to our sensory perceptions. Given such a picture, however, an ability on our part to directly influence the movements of our limbs might well seem problematic. For Berkeley would then appear to be committed to holding that we are passive with respect to our perceptions, active with respect to our limbs, while nonetheless insisting that our limbs just are collections of perceptions. On pain of committing Berkeley to an inconsistent triad, it might therefore be objected that we should not attribute to him any view according to which we might be genuine causes with respect to the movements of our bodies.

As before, however, this objection rests on an ultimately unwarranted simplifying assumption. For the apparent inconsistency arises only if we attribute to Berkeley the view that we must be either wholly active or wholly passive with respect to each object of experience. ${ }^{40}$ His carefully worded statements that we are "somewhat active in most perceptions;" that, compared with our ideas of imagination, our sensory perceptions (merely) have "not a like 
dependence on our will;" and even his remark to Johnson that "the soul of man is passive as well as active" gives us good reason to doubt that Berkeley's considered view is that we must be either completely active or completely passive with respect to each particular object of experience (N, 672a; Dialogues, 3:235 emphasis added; Works, 2:293). Furthermore such an assumption — while perhaps initially tempting — is on its face philosophically implausible. Our everyday experience of our own bodies provides one source of counterexamples: my experience of my hand being waved in front of my face would seem to be partly under my control—I can move it more quickly, more slowly, or not at all—but also partly not under my control—I cannot directly make it appear purple, or pineapple-shaped for example. In other cases, of course, the assumption will be more plausible as for example when we focus on ideas of imagination and sensory perceptions of things like my desk, the house across the street, and the sun. Even then, however, the suggestion that we are wholly active or wholly passive with respect to an object of thought is probably best treated as a simplification or idealization. My imaginary experiences are usually more fully under my control, but not always, perhaps not ever, wholly under my control. They are often limited by recurring patterns, by my dispositions, and by my prior experiences. Likewise, I am in general more passive with respect to my sensory experiences, but not always, and perhaps not ever, wholly passive with respect to them. My mind and my will surely help to shape even the purest of sensory experiences, and, as Berkeley frequently points out, I am at least active with respect to them to the extent that I can shut them out altogether by averting my gaze, by turning my head, etc. If, however, it is granted that we are both partially active and partially passive with respect to the movements of our own bodies, then the tension originally proposed disappears. Berkeley could hold, for example, that I am maximally (perhaps completely) active with respect to my imagining a circus, maximally (perhaps completely) 
passive with respect to my perception of the sun, and yet something in between with respect to the ideas that constitute my limbs.

(4) A fourth and final source of worries that might be thought to stand in the way of Berkeley's embracing a more robust view of human agency than almost-occasionalism concerns the possibility of causal interactions between finite substances. Since, on Berkeley's idealism, my limbs will typically be constituted not only by my perceptions but also by the perceptions of other finite agents, the proposal that I might be an immediate cause of the movement of my legs suggests that I might thereby be an immediate cause of alterations in the perceptions of other finite agents. Although nothing in Berkeley's conception of causation per se appears to prohibit such a consequence, ${ }^{41}$ it is tempting to suppose that, for him, one finite creature may influence another finite creature only indirectly through God's mediating activity. In short, it is tempting to suppose that Berkeleyan minds, like Leibnizian monads, either must be, or simply are, causally isolated from one another.

Fortunately, there is a relatively easy way for Berkeley to accommodate the assumption of causal isolation while still warding off the specter of almost-occasionalism. Even if it is taken for granted that finite minds cannot immediately act on one another, Berkeley could still insist that we enjoy a direct causal influence over our own bodies insofar as they are constituted by our own perceptions. He could thus hold, for example, that when I am said to move my legs myself, what I really do, strictly speaking, is immediately influence (with God's concurrence) my own perceptions of my legs, with the alterations of my perceptions in turn serving as occasional causes for God's giving rise to corresponding perceptions in other finite minds. ${ }^{42}$ Although the claim that "I move my legs myself" would, on this view, require some philosophical interpretation by the learned, there would nonetheless be a firm metaphysical foundation in my 
concurring activity for Berkeley's insistence that I may be active with respect to my body in a way that I am not active with respect to any other body (i.e. in virtue of the fact that I am an immediate cause with respect to at least some of the perceptions constituting it). While the scope of human activity on such a model would remain relatively modest, Berkeley could nonetheless legitimately maintain that his view differs from occasionalism not only in explicitly making our wills active, but also in granting to us an immediate influence over the objective world in virtue of our ability to directly influence the movements of our own bodies.

While Berkeley could thus embrace the causal isolation of finite minds and still significantly distance his own view from almost-occasionalism, we might nonetheless wonder if he could not go further still and grant to finite minds the ability to immediately influence other finite minds in virtue of the immediate causal influence they enjoy over their own bodies. Remarkably, in spite of the naturalness of the assumption of causal isolation, nothing in Berkeley's texts or metaphysics obviously commits him to denying that one finite mind might directly influence another finite mind—assuming, of course, God's active concurrence. In order to make this admittedly contentious suggestion more plausible, let us close by briefly taking up three considerations that might otherwise appear to speak definitively against it.

The first is a well-known passage from the Principles which at a first pass appears to imply straightforwardly that no finite spirit may influence the perceptions of any other finite spirit: $<\mathrm{ext}>$

For, it is evident that in affecting other persons, the will of man has no other object, than barely the motion of the limbs of his body; but that such a motion should be attended by, or excite any idea in the mind of another, depends wholly on the will of the Creator. $\mathrm{He}$ 
alone it is who upholding all things by the word of His power, maintains that intercourse between spirits, whereby they are able to perceive the existence of each other. (Principles, 147)

$</$ ext $>$

On one reading, this passage would strongly suggest that, for Berkeley, my ability to influence the perceptions of other finite minds depends entirely upon God's coordinating activity. I will that my hand go up, and with God's concurrence, I typically contribute to an alteration in my own perceptions. But, on this reading, that action's having any effect upon any other finite mind requires more than God's concurrent assistance; it requires his treating the alterations in my perceptions as occasions for producing corresponding perceptions in other finite minds.

As Robert McKim has pointed out, however, the Principles passage might be read in another way. ${ }^{43}$ When Berkeley says that it is God alone who " upholding all things by the word of His power', maintains that intercourse between spirits whereby they are able to perceive the existence of each other," he might mean that God must be the total immediate cause of all of our perceptions of other finite spirits. But he could also mean simply that God's conserving and concurring assistance is a necessary condition for finite spirits to act upon one another. Such a reading seems not only consistent with the letter of what Berkeley writes in Principles 147, but also with the spirit of its larger message, namely, that "God is known as certainly and immediately as any other mind or spirit whatsoever." For on this reading, our experiences of other finite creatures would provide evidence for both their existence and God's, while our experiences of the "infinitely more numerous and considerable" effects of nature would provide evidence of God's existence alone. 
The second consideration that might be thought to conclusively block the possibility that one finite spirit might immediately influence the perceptions of another is rooted in Berkeley's professed allegiance to commonsense. For commonsense might be thought to dictate that the bodily movements of one finite agent may affect perceptions in another finite agent only indirectly: I waive my hand, immediately cause changes in light patterns, and indirectly cause your perception of my hand; I shout, immediately cause a disturbance in the air, and indirectly your perception of my words. For Berkeley, however, the mediating role that might otherwise be assigned to physical bodies - air, water, light, etc. — can only be assigned to God's coordinating activity in the world. One might therefore conclude that, given Berkeley's idealism, the commonsense intuition that I cannot immediately cause perceptions in other finite minds without causally intervening in the world forces him to the view that I can only be an occasional cause of perceptions in other finite minds.

Again, however, the case here is less definitive than it might seem at first pass. ${ }^{44}$ For the commonsense intuition that I can only indirectly influence your perceptions gains much of its force from the assumption of a materialist ontology. In a world of mind-independent media and objects, the supposition that I might alter your perceptions without altering the common material world in which we move, live, and interact is tantamount to postulating something on the order of psychokinesis. And that should indeed strike us as spooky and unintuitive. If, however, the idealist is right, and what we take to be material objects are constituted by perceptions immediately perceived by other finite minds, then the intuition that I can only indirectly influence your perceptions looks much less compelling. For if my hand is constituted in part by perceptions in the minds of other finite spirits, the claim that I can directly influence your perceptions requires nothing more than that I be able to exert a direct influence over the 
movements of my own body. And that assertion, of course, might well be thought to have as much claim to commonsense as any thesis about our inability to directly influence the perceptions of other finite spirits. The case from commonsense against our being able to immediately influence the perceptions of other finite minds in virtue of our being able to immediately influence the movements of our own bodies thus turns out to be far less compelling than one might have otherwise imagined.

Finally, it might be thought that Berkeley's purported rejection of "blind agency" precludes the possibility that one finite mind might directly influence the perceptions of another finite mind. As Kenneth Winkler has argued in detail, among Berkeley's contemporaries it was widely held that any volition presupposes a prior cognition of the state of affairs being willed. ${ }^{45}$ Although Berkeley does not explicitly endorse the doctrine of no blind agency in either the Principles or the Dialogues, there is textual evidence, especially in the Notebooks, but also in Alciphron and Siris, that he found at least some version of it appealing (see, for example, N, 674, 743, 812, 841-2; Alciphron, VII 18; Siris, 322).

If the thesis of no blind agency is taken strictly, so that it entails that a finite agent cannot will a state of affairs without first having an exact idea of that state of affairs, it will present a serious obstacle to immediate causal interaction between finite minds in the Berkeleyan system. The crux of the problem lies in the fact that even where two agents have perceptions of the same body, they will seldom, perhaps never, have exactly similar perceptions. To take a typical case, when I wave to a friend, I have perceptions, as we would put it, of the back of my hand, while my friend has perceptions of the front of my hand. Even if it is granted that Berkeley's idealism per se allows for the possibility that in moving my hand back and forth I immediately influence my friend's perceptions, the denial of blind agency, when coupled with perceptual variation, 
would seem to preclude it. For that thesis, taken strictly, would require that in order to bring about a change in the perceptions of my friend, I would have to first have those exact perceptions — or exact ideas of those perceptions — clearly in mind myself. I would, as it were, have to see or imagine my hand from the perspective of my friend. Given our different experiential perspectives, however, it seems that that might never, perhaps even in principle, be the case, and so I might never be in a position to immediately influence another finite agent's perceptions of my body.

While the no blind agency thesis raises an interesting set of concerns with respect to how far Berkeley can extend the scope of human agency, we should, I think, be hesitant to attribute a strict version of the doctrine to him for at least three related reasons. First, the textual basis for ascribing the thesis of no blind agency to Berkeley is, in fact, quite thin. While it might nonetheless be sufficient for attributing the doctrine in some form or other to Berkeleyespecially in light of its wide acceptance among his contemporaries - his texts clearly do not give us a full picture of his understanding of the doctrine, nor how he sees it fitting into his philosophical system as a whole. Second, what Berkeley does tell us suggests that his driving interest in the thesis is that the will and understanding not be treated as two distinct and separate faculties; he gives no indication that he is drawn to the exceedingly strong position that every aspect of every one of our actions must be cognitively transparent to us. Third, it is clear that, even bracketing concerns over causal interactions between finite minds, a strict reading of the no blind agency thesis would go too far for Berkeley: it would not only rule out one finite mind immediately influencing another finite mind, but also a single finite mind's conjuring novel ideas of the imagination (since doing so would require the agent to first represent the ideas to be imagined, thus launching an infinite regress). ${ }^{46}$ There are thus good reasons to suppose that 
Berkeley favored —or would have favored, if he had worked out the doctrine more fully—a somewhat relaxed version of the no blind agency thesis, one not committed to the sort of perspectival omniscience that would otherwise raise such obvious trouble for the possibility of causal interactions between finite minds. Indeed, it seems reasonable to suppose that, had he confronted the issue directly, Berkeley might well have tempered his understanding of the no blind agency thesis specifically in the hopes of assigning as wide a scope to human activity as any sensible materialist, and capturing, in the most straightforward way available to him, the commonsense notion that "we move our legs ourselves."

\section{Conclusion}

Berkeley's commentators have long seen vacillation and contradiction lurking in his account of human agency. Once his discussion of human agency is placed in its appropriate historical context, however, one can see in his texts a consistent endorsement of concurrentism as opposed to occasionalism or mere conservationism. Furthermore, once we appreciate this endorsement, we can see why, given other central commitments of his system, he would have resisted contemporary efforts to push him towards a thoroughgoing occasionalism. Finally, reflection on his dual commitment to concurrentism and idealism suggests that he might assign a widerperhaps a much wider - scope to human agency than has generally been assumed. Although Berkeley does not provide us with a fully explicated philosophy of mind or spirit — that was to be the topic of Part II of the Principles - what he does offer us suggests a coherent, philosophically interesting, and characteristically subtle view of human agency. 
${ }^{1}$ I would like to thank Paul Hoffman, Andrew Janiak, Nick Jolley, Sam Levey, Alan Nelson, Tad Schmaltz, Alison Simmons, and Kenneth Winkler for their helpful comments on earlier drafts of this paper. This essay won the 2007 Colin and Ailsa Turbayne International Berkeley Essay Prize Competition, and I would like to express my appreciation to both the prize's founders and its administrators in the Department of Philosophy at the University of Rochester. ${ }^{2}$ All quotations from Berkeley’s writings are taken from The Works of George Berkeley, Bishop of Cloyne, eds. A. A. Luce and T. E. Jessop (New York: Thomas Nelson and Sons Ltd., 1948). I have used the following abbreviations and conventions: Alciphron, or The Minute Philosopher, dialogue $\mathrm{x}$, section y = Alciphron, x:y; De Motu or Sive de motus principio \& natura et de causa communicationis motuum, paragraph $\mathrm{x}=$ De motu, $\mathrm{x}$; Notebooks (also known as Philosophical Commentaries) entry $\mathrm{x}=N, \mathrm{x}$; Part I of A Treatise concerning the Principles of Knowledge, section $\mathrm{x}=$ Principles, $\mathrm{x}$; Siris: A Chain of Philosophical Reflexions and Enquiries, section x; The Works of George Berkeley, Bishop of Cloyne, vol. x, page y= Works, x:y; Three Dialogues between Hylas and Philonous, dialogue x, page y = Dialogues, x:y.

${ }^{3}$ See, for starters, Principles, 25, 26, 28, 137; Dialogues, 3: 236-40; N, 107, 461, 548, 699.

${ }^{4}$ See, for example, George Pitcher, "Berkeley on the Mind's Activity," American Philosophical Quarterly 18 (1981): 221-7; and Jonathan Bennett, Learning from Six Philosophers, Volume 2 [Six Philosophers] (Oxford: Oxford University Press, 2001), 165-167.

${ }^{5}$ See, for example, Anita Fritz, “Berkeley’s Self-Its Origin in Malebranche," Journal of the History of Ideas 15:4 (1954): 554-572 .

${ }^{6}$ See, for example, Nicholas Jolley, "Berkeley and Malebranche on Causality and Volition," in Central Themes in Early Modern Philosophy: Essays Presented to Jonathan Bennett, eds. J. A. 
Cover and Mark Kulstad (Indianapolis: Hackett, 1990), 227-244; and Robert McKim, “Berkeley on Human Agency,” History of Philosophy Quarterly 2 (1984): 181-194.

${ }^{7}$ For helpful overviews of concurrentism, mere conservationism, and occasionalism see especially Alfred Freddoso, “God's General Concurrence with Secondary Causes: Pitfalls and Prospects," ["Pitfalls and Prospects"] American Catholic Philosophical Quarterly 52:8 (1994): 131-156 ; "God's General Concurrence with Secondary Causes: Why Conservation is Not Enough," ["Why Conservation is Not Enough"] Philosophical Perspectives 5 (1991): 553-585 ; and "Medieval Aristotelianism and the Case against Secondary Causation in Nature," ["Medieval Aristotelianism"] in Divine and Human Action: Essays in the Metaphysics of Theism, ed. Thomas V. Morris (Ithaca: Cornell University Press, 1988), 75-118. See also, Philip Quinn, "Divine Conservation, Secondary Causes, and Occasionalism," in Divine and Human Action: Essays in the Metaphysics of Theism, ed. Thomas V. Morris (Ithaca: Cornell University Press, 1988): 50-73. I owe the term "mere conservationism" to Freddoso.

${ }^{8}$ See, Thomas Aquinas, Quaestiones Disputatae de Potentia Dei [De potentia], in Raymund M. Spiazzi, ed. Quaestiones disputatae (Rome: Marietti, 1964-1965 ) question 3, articles 1-4 ; available in English translation in On the Power of God, trans. Laurence Shapcote (London: Burns, Oates \& Washbourne, 1932-1934 ). See also, Thomas Aquinas, Summa theologiae, [ST] book 1, question 45, articles 1-5, in S. Thomae Aquinatis Doctoris Angelici Opera Omnia, vols. 4-12 (Rome: Commissio Leonina, 1882-); available in English translation in Summa theologiae, trans. Laurence Shapcote (New York: Benzinger, 1947-1948).

${ }^{9}$ Albertus Magnus, Commentarii in II Sententiarum, dist. 35. section 1, article 7, in Opera Omnia (Paris, 1894), vol. 27. Thomas Aquinas, De Potentia, question 3, article 7; ST book 1, questions 103 and 105; Summa contra Gentiles [SCG] book 3, part 1, chapters 64-67, 69, 70, 
75-77; available in English translation in Summa contra gentiles, trans. Anton C. Pegis et al. (Notre Dame, Ind.: University of Notre Dame Press, 1975).

${ }^{10}$ Luis de Molina, S. J., Liberi Arbitrii cum Gratiae Donis, Divina Praescientia, Providentia, Praedestinatione et Repobatione Concordia [Concordia] ( $2^{\text {nd }}$ edition: Antwerp, 1595), modern edition edited by Johann Rabeneck, S. J. (Ona and Madrid, 1953), part 2, disputations 25-28. Francisco Suarez, Disputationes Metaphysicae (Salamanca, 1597), disputations 18 and 22; modern edition edited by Carolo Berton as vols. 25 and 26 of Suarez, Opera Omnia: Novo Editio (Paris, 1866; reprinted in two volumes at Hildesheim, 1965); available in English translation in On Efficient Causality: Metaphysical Disputations 17, 18, and 19, trans. Alfred J. Freddoso, (New Haven, Connecticut: Yale University Press, 1994); and On Creation, Conservation, and Concurrence: Metaphysical Disputations 20-22, trans. Alfred J. Freddoso, (South Bend, IN: St. Augustine's Press, 2002).

${ }^{11}$ Robert Boyle, "The Origin of Forms and Qualities according to the Corpuscular Philosophy (1666)," "The Excellency and Grounds of the Mechanical Hypothesis (1674)," "A Free Inquiry into the Vulgarly Received Notion of Nature (1686)," in Works, eds. Michael Hunter and Edward B. Davis (London: Pickering and Chatto, 1999-2000), vols. 5, 8, and 10. For a guide to Boyle's often scattered remarks on concurrentism, see Timothy Shanahan, "God and Nature in the Thought of Robert Boyle," Journal of the History of Philosophy, 26:4 (1988): 547-567, and Peter Anstey, The Philosophy of Robert Boyle (New York: Routledge, 2000), especially 165-71, 181. Gottfried Leibniz, On the Correction of Metaphysics and the Concept of Substance (1694), in Die philosophischen Schriften von Gottfried Wilhelm Leibniz, [Philosophischen Schriften] ed. C. I. Gerhardt (Berlin: Weidman, 1875-90) vol. 4, pp. 468-70, in English translation by Leroy E. Loemker, Philosophical Papers and Letters, $2^{\text {nd }}$ edition (Dordrecht: D. Reidel, 1669); “On 
Nature Itself (1698)" in Philosophischen Schriften, vol. 7, 302-8, in English translation R. Ariew and D. Garber, Philosophical Essays (Indianapolis: Hackett, 1989), 149-167; and Theodicy in Philosophical Schriften, vol. 6 (in English translation E. M. Huggard (La Salle, Illinois: Open Court, 1985). For a guide to Leibniz's often scattered remarks on concurrentism, see, Sukjae Lee, "Leibniz on Divine Concurrence" Philosophical Review 113:2 (2004): 203-248; Jeffrey McDonough, "Leibniz: Creation and Conservation and Concurrence" The Leibniz Review, forthcoming; and Robert Sleigh, "Leibniz on Malebranche on Causality," in Central Themes in Early Modern Philosophy, eds. Jan Cover and Mark Kulstad (Indianapolis: Hackett, 1990) 161193.

${ }^{12}$ Indeed, Freddoso reports that William Durandus "is the only well-known medieval proponent of mere conservationism, or at least the only one cited by sixteenth and seventeenth-century writers," "Pitfalls and Prospects," 134. As we will see later on, in arguing against mere conservationism, Berkeley follows tradition in singling out Durandus for criticism.

${ }^{13}$ Francisco Suarez, Disputationes Metaphysicae, disputation 22, section I.6-7. See also Luis de Molina, Concordia, part 2, disputation 25, section 14. For a contemporary discussion, see Freddoso, "Why Conservation is Not Enough," 566-572.

${ }^{14}$ Francisco Suarez, Disputationes Metaphysicae, disputation 22, section I.13.

${ }^{15}$ Thomas Aquinas, De Potentia, question 6, article 2, ad. 3.

${ }^{16}$ Luis de Molina, Concordia, part 2, disputation 25, section 15; Francisco Suarez, Disputationes Metaphysicae, disputation 22, section I.11. For contemporary discussion, see Freddoso, "Why Conservation is Not Enough," 572-577.

${ }^{17}$ Significantly, I do not take occasionalism to be the doctrine that merely some creaturely events serve as the occasions for God's direct causal intervention. Most mere conservationists and 
concurrentists alike could accept that God might, and sometimes does, directly intervene in the causal order of the world (literally) on occasion. And, indeed, Berkeley himself accepts that idea-idea causation is always occasional. The interesting position to be defended or denied is therefore that creaturely events can only be occasional causes, not that they might, or sometimes are, occasional causes.

${ }^{18}$ An attitude epitomized by Molina's remark, "Everyone rejects this position [of occasionalism], and St. Thomas justifiably calls it stupid. For what could be more stupid than to deny what is obvious from experience and sense perception?" Concordia, p. 160; quoted in Freddoso, “Medieval Aristotelianism," 99.

${ }^{19}$ See, for example, Nicholas Malebranche, De la recherche de la vérité, book 6, part 2, chapters 3 and 9, and Éclaircissement 15 in André Robinet, dir., Oeuvres completes de Malebranche, 20 vols. (Paris: J. Vrin, 1958-1967), vols 1-3; selections available in English translation in Steven Nadler, trans. and ed., Nicholas Malebranche: Philosophical Selections (Indianapolis, Indiana: Hackett), 92-144.

${ }^{20}$ See, especially, De ipsa natura, Philosophischen Schriften, vol. 4, 508-509; in English translation in Roger Ariew and Daniel Garber, G. W. Leibniz: Philosophical Essays (Indianapolis, Indiana: Hackett 1989) 159-160, and Theodicy, section 393.

${ }^{21}$ Leibniz, Theodicy, section 399.

${ }^{22}$ Special thanks to Kenneth Winkler for drawing my attention to Principles, 66 and the passage below from the Second Dialogue, as well as for his helpful correspondence with respect to both passages.

${ }^{23}$ See also Johnson's letter to Berkeley 10 September 1729 (especially paragraphs 2 and 3), and Berkeley's reply of 25 November 1729 (again especially paragraphs 2 and 3). For a traditional 
argument that mere conservationism collapses into deism, see, for example, Suarez, Disputation

\section{2, Section 1.}

${ }^{24}$ Pitcher, "Berkeley on the Mind's Activity," 222

${ }^{25}$ Jolley, "Berkeley and Malebranche on Causality and Volition," 227

${ }^{26}$ See, also Dialogues 2:214 and N, 230.

${ }^{27}$ See, De Motu, 25; Principles, 28; Dialogues, 1:196, 2:218; N, 499, 699.

${ }^{28}$ Cf. Principles, 89: "Thing or being is the most general name of all, it comprehends under it two kinds entirely distinct and heterogeneous, and which have nothing in common but the name, to wit, spirits and ideas. The former are active, indivisible substances: the latter are inert, fleeting, dependent beings, which subsist not by themselves, but are supported by, or exist in minds of spiritual substances."

${ }^{29}$ It is perhaps worth emphasizing that Berkeley's dualism does not commit him to the view that all spirits are completely or wholly active. Indeed, Christian philosophers in general are committed to the view that only God can be wholly active, and Berkeley explicitly tells Johnson that "the soul of man is passive as well as active, I make no doubt" (Works, 2:293).

${ }^{30} \mathrm{Cf}$. Jonathan Bennett: "When we look at our ideas, Berkeley says, we do not find them to be active ... I cannot evaluate this, because I do not know what thought-experiment I am being invited to perform. How do I go about looking for activity in my ideas?" Six Philosophers, 159.

${ }^{31}$ Nicholas Jolley has recently argued that Berkeley’s dualism has its roots in theological concerns, and more specifically, in the Genesis doctrine that man is made in the image of God. See his, "Berkeley and Malebranche on Causality," 234-8; see also Edward Craig, The Mind of God and the Works of Man (Oxford: Oxford University Press, 1987), Chapter 1. 
${ }^{32}$ That is, the narrow sense which distinguishes ideas from notions, as in the first editions of the Principles and the Dialogues. For a brief discussion of Berkeley's narrow and wide senses of “idea,” see Robert Adams, “Berkeley's 'Notion’ of Spiritual Substance,” Archiv für Geschichte der Philosophie 55 (1973), reprinted in George Berkeley: Critical Assessments, Volume III, Matter and the External World, Minds and Notions, ed. Walter E. Creery, (New York: Routledge, 1991), 433.

${ }^{33}$ For a detailed discussion of Berkeley's doctrine of notions, see Adams, 'Berkeley's 'Notion' of Spiritual Substance."

${ }^{34}$ Lorne Falkenstein, “Berkeley’s Argument for Other Minds,” History of Philosophy Quarterly 7:4 (1990): 431-440. For discussion, see also, Kenneth Winkler, Berkeley: An Interpretation (Oxford: Clarendon Press, 1989, 2001), 285-286, and Bennett, Six Philosophers, 167-169. ${ }^{35}$ For a more thorough discussion and defense of the following points than can be offered in the present context, see especially Francisco Suarez, Disputationes Metaphysicae, disputation 22, as well as, the helpful discussion—-from which I draw upon here—in Freddoso, "Pitfalls and Prospects," "Medieval Aristotelianism," and "Why Conservation is Not Enough." For a heuristic analogy of the cooperative activity of God and a creature one might try thinking of the cooperative activity of an electrical current and a toaster: the electricity and the toaster might plausibly be thought to act through a single action in producing a "toasting" (since neither the toaster nor the electricity by itself produces a toasting activity); likewise, the electricity and toaster might plausibly be held to bring about a unified effect, namely, the whole "toasting" (rather than say the electricity's bringing about half of the "toasting" and the toaster's bringing about the other half); finally, in spite of their acting through a single action in bringing about a unified effect, it nonetheless seems plausible to attribute the fact that a "toasting" takes place_-as 
opposed to (say) a blending, a beating, or a heating - to the toaster since if the electricity had concurred with a different appliance a different effect would have been produced. (Special thanks to Peter Millican for starting me thinking about electrical models in connection with concurrentism.)

${ }^{36}$ It might be worth noting that God's immediate conservation of a creature (from underneath as it were) was generally held to be consistent with its undergoing change within the order of nature. Thus, in thinking about divine conservation, it might be helpful to think of it as analogous in some respects to the conservation of energy. The suggestion that the total energy of the world is conserved is not meant to imply that energy cannot change from say, electrical to kinetic, from kinetic to chemical, etc.

${ }^{37}$ Malebranche, of course, famously attempted to collapse this traditional distinction between the order of creation-conservation and the order of concurrence, arguing that the principle of continuous creation precludes the possibility of creatures acting within the order of nature, and thus that it entails occasionalism. Although this is not the place to argue the point, I think this general and admittedly clever Malebranchian line of argument is much less convincing than is widely supposed. For discussion, see Jeffrey McDonough, "Leibniz: Creation and Conservation and Concurrence," Leibniz Review, forthcoming; Andrew Pessin, "Does Continuous Creation Entail Occasionalism? Malebranche (and Descartes)," Canadian Journal of Philosophy (2000): 413-440, and Kenneth Winkler, “Continuous Creation," unpublished (2007).

${ }^{38}$ See, for example, Molina, Concordia, disputation 26, section 12.

${ }^{39}$ Michael Ayers, "Perception and Action," in Knowledge and Necessity, Royal Institute of Philosophy Lectures, Volume Three, 1968-1969 (New York: St. Martin’s Press, 1970): 95. 
${ }^{40}$ One shouldn't, of course, confuse any thesis about our activity or passivity with respect to our ideas, with a thesis about the activity or passivity of the ideas themselves. (To be active with respect to a hammer is one thing, for a hammer be itself active is another.) Likewise, one shouldn't assume that Berkeley's semantic thesis that ideas (because they are passive) cannot represent spirits (because they are active) precludes us from being active with respect to our ideas.

${ }^{41}$ In his nice discussion of Berkeley's views on causation, Kenneth Winkler, for example, argues that an event, for Berkeley, must meet three conditions in order to be counted as a cause: (i) "it is followed by another event;" (ii) "supposing only that God's decrees remain the same, an event of the first type must be followed by an event of the second type;" and (iii) "the first event is a volition" (Berkeley: An Interpretation , 112). Clearly nothing in these conditions at least speaks against the possibility of one finite agent acting immediately on another.

${ }^{42}$ One should not suppose that in suggesting that I influence some perceptions belonging to the collection of ideas that constitutes my hand, but not others, Berkeley would necessarily fall into the trap of the divided effect discussed above. For that difficulty arises not from supposing that there are two effects that are brought about—one concurrently and one occasionally—but in supposing that the effect brought about concurrently is to be understood as two effects-one brought about by me and one by God.

${ }^{43}$ McKim, "Berkeley on Human Agency," 189.

${ }^{44}$ McKim has emphasized this point as well, see his "Berkeley on Human Agency," 191.

${ }^{45}$ Winkler, Berkeley: An Interpretation, 207-216.

${ }^{46}$ Cf. Bennett, Six Philosophers, 191-192. 